УДК 615.322:[582.681.81:581.44].014.453:539.1.06

\title{
ИЗУЧЕНИЕ ВОЗМОЖНОСТИ СТЕРИЛИЗАЦИИ ПОБЕГОВ ИВЫ БЕЛОЙ (SALIX ALBA L.) ИОНИЗИРУЮЩИМ ИЗЛУЧЕНИЕМ
}

\author{
() О.О. Фролова ${ }^{\prime *}$, А.С. Сауикина ${ }^{2}$, М.В. Мазурина ${ }^{I}$, А.Ю. Айрапетова ${ }^{l}$, Е.Г. Компанцева ${ }^{1}$, \\ Е.В. Компанцева ${ }^{l}$
}

${ }^{1}$ Пятигорский медико-фрармацевтический институт - фрилиал

Волгоградского государственного медицинского университета, пр. Калинина, 11, Пятигорск, 357532 (Россия), e-mail: oxifarm@mail.ru

${ }^{2}$ Санкт-Петербургская государственная химико-фрармацевтическая академия, ул. проф. Попова, 14, Санкт-Петербург, 197376 (Россия)

\begin{abstract}
Определено содержание микроорганизмов в образцах побегов Salix alba L., подвергнутых обработке ионизирующим излучением (0,25-5 кГр). После обработки излучением, начиная с минимальной дозы, порошок побегов S. alba соответствует рекомендуемым требованиям по показателю «Микробиологическая чистота», что позволяет говорить об эффективности предлагаемого метода стерилизации. Ионизирующее излучение приемлемо для обработки побегов $S$. alba, поскольку существенно не влияет на качественный состав и количественное содержание основных БАВ (флавоноидов, дубильных веществ, салицина). После проведения стерилизации ионизирующим излучением возможно создание на основе нативных побегов $S$. alba лекарственных форм для перорального применения.

Ключевые слова: ионизирующее излучение, стерилизация, микробиологическая чистота, лекарственное растительное сырье, побеги Salix alba L.
\end{abstract}

\section{Введение}

В современном производстве фитопрепаратов чаще всего проводится экстрагирование лекарственного растительного сырья. Однако традиционные методы экстракции имеют ряд существенных недостатков. Во-первых, они приводят к частичному разрушению биологически активных веществ (БАВ) вследствие гидролиза и термической деструкции, во-вторых, часть БАВ остается в шроте, в-третьих, сам шрот яв-

Фролова Ольга Олеговна - ведущий специалист отдела аспирантуры и докторантуры, кандидат

фармацевтических наук, тел./факс: (8793) 32-92-67, e-mail: oxifarm@mail.ru

Саушкина Анна Степановна - старший научный сотрудник кафедры фармацевтической химии, кандидат фармацевтических наук, доцент, e-mail: annasaushkina@list.ru

Мазурина Майя Викторовна - преподаватель кафедры биологической химии и микробиологии, факс: (8793) 32-92-67

Айрапетова Ася Юрьевна - доцент кафедры фармацевтической химии, кандидат фармацевтических наук, e-mail: asyapgfa@mail.ru

Компаниева Евгения Геннадьевна - студентка

Компанцева Евгения Владимировна - профессор

кафедры фармацевтической химии, доктор

фармацевтических наук, профессор,

e-mail: dskompanceva@mail.ru ляется опасным для экологии отходом, требующим соответствующей утилизации, в-четвертых, сам процесс экстракции требует специального дорогостоящего оборудования и использования не всегда безопасных растворителей (например, огнеопасный этиловый спирт) [1].

В то же время возрастает интерес к лекарственным формам, содержащим нативное лекарственное растительное сырье (ЛРС). Порошки измельченных растений тысячелетиями назначались внутрь в традиционной индийской и китайской медицине. Известны современные биологически активные добавки (БАД), содержащие нативное ЛРС. Идея базируется на введении всего комплекса биологически активных веществ в неизменной форме [2]. Однако прием внутрь нативного лекарственного сырья, не

\footnotetext{
* Автор, с которым следует вести переписку.
} 
прошедшего термическую обработку в процессе экстракции, небезопасен с точки зрения контаминирования опасными для здоровья человека микроорганизмами.

Выбранный способ стерилизации ЛРС - гамма-излучение - позволяет не только снизить содержание микроорганизмов, но и не вызывает образования токсичных, канцерогенных и мутагенных веществ [3, 4]. При этом на примере ряда видов ЛРС показано, что данный вид излучения практически не изменяет состав биологически активных комплексов ЛРС и не влияет на специфическую фармакологическую активность [5, 6].

В качестве объекта были выбраны побеги ивы белой - Salix alba L. (сем. Salicaceae). В США выпускается БАД «Кора ивы белой - White Willow Bark» («Nature's Way») в форме капсул, содержащих 400 мг измельченного сырья [7]. Использование побегов $S$. alba имеет очевидные преимущества по сравнению с корой, так как их заготовка проще и экологичнее. Наряду с корой побеги $S$. alba проявляют противовоспалительное и анальгетическое действие [8], что обусловливает возможность использования во вспомогательной терапии заболеваний опорно-двигательного аппарата. Данное сырье содержит богатый комплекс БАВ (флавоноиды, дубильные вещества, фенолокислоты, салицин, кислота аскорбиновая, полисахариды и др.), которые могут разрушаться при нагревании. В связи с этим разработка отечественного препарата, отвечающего современным требованиям по микробиологической чистоте к лекарственным средствам для приема внутрь, на основе стерилизованных нативных побегов $S$. alba, несомненно, актуальна.

Цель работы - определить эффективность стерилизации нативного лекарственного растительного сырья - побегов $S$. alba -ионизирующим излучением и установить отсутствие его влияния на содержание основных биологически активных веществ. Соответствие стерилизованного сырья нормативным требованиям откроет перспективы создания на его основе лекарственных форм для приема внутрь.

\section{Экспериментальная часть}

Образцы однолетних побегов S. alba (неодревесневшие ветви длиной 15-30 см с листьями) были заготовлены в Ставропольском крае (в окрестностях Пятигорска, на левом берегу реки Подкумок, в местах повышенного увлажнения) в июле 2010 г. после окончания цветения. Срезку побегов проводили ножом. Образцы были определены профессором В.А. Компанцевым. Сушку проводили в естественных условиях.

Для измельчения побегов $S$. alba, имеющих волокнистую структуру, была применена траворезка, с помощью которой достигали размера частиц 3 мм. Дальнейшее измельчение сырья до размера частиц менее 1 мм (оптимального для приема внутрь) проводили на мельнице с ротационным ножом. Стандартного состояния измельченного сырья достигали просеиванием через сито соответствующего диаметра. Очистку от пыли осуществляли просеиванием через сито с размером отверстий 0,2 мм.

Обработку измельченных побегов $S$. alba ионизирующим излучением проводили на базе государственного бюджетного образовательного учреждения высшего профессионального образования «СанктПетербургская государственная химико-фармацевтическая академия» Министерства здравоохранения Российской Федерации. В работе использовался гамма-облучатель «Исследователь». Суммарная активность источников гамма-излучения радиоактивного кобальта ${ }^{60}$ Со составила 19460 Кюри; высота рабочей камеры - 240 мм, диаметр - 150 мм, рабочий объем - 4,4 л. Средняя мощность дозы гамма-излучения в рабочем объеме камеры составила 42,5 Гр/мин [4,9].

Дозиметрию проводили химическим методом с использованием ферросульфатного дозиметра. Ошибка определения величины дозы составила $\pm 2 \%$. Дозу гамма-излучения контролировали химическим методом с помощью ферросульфатного дозиметра с погрешностью $\pm 2 \%$ [9]. Величину поглощенных доз варьировали в интервале от 0,5 до 5 кГр.

Определение микробиологической чистоты выполняли на кафедре биологической химии и микробиологии Пятигорского медико-фармацевтического института - филиала Волгоградского государственного медицинского университета согласно требованиям Государственной фармакопеи (ГФ) XII издания (ОФС 42-0067-07 «Микробиологическая чистота») [10] и Изменениям №2 от 01.01.2002 к ОФС ГФ ХІ издания «Испытание на микробиологическую чистоту» [11]. Испытание включало количественное определение жизнеспособных бактерий и грибов, а также выявление определенных видов микроорганизмов, наличие которых недопустимо в нестерильных лекарственных средствах.

Определение аэробных бактерий и грибов. Для количественного определения аэробных бактерий и грибов отбирали 1 г образца, добавляли 100 мл разбавителя, встряхивали на шюттель-аппарате и получали первоначальный смыв 1:100, из которого делали ряд последовательных разведений до $10^{-5}$. Посевы прово- 
дили двухслойным агаровым методом. Для каждого разведения во время посева использовали по 2 чашки Петри. Посевы инкубировали при 32,5+2,5 C на среде №1 для определения бактерий и при $22,5+2,5{ }^{\circ} \mathrm{C}$ на среде №2 для определения грибов. Через 24-48 ч чашки просматривали и предварительно учитывали результат. По окончании испытания подсчитывали число колоний на двух чашках, находили среднее арифметическое и, умножая его на показатель разведения, определяли число колониеобразующих единиц (КОЕ) в 1 г образца.

Onpeделение E. Coli. Для количественного определения E. coli делали посев в 9 мл среды №3 следующим образом: исходный смыв в количестве 1 мл вносили в первую пробирку, тщательно перемешивали и переносили 1 мл во вторую пробирку, снова перемешивали и переносили 1 мл в третью пробирку. Посевы инкубировали при $32,5+2,5^{\circ} \mathrm{C}$ в течение $24-48$ ч. Для подтверждения наличия роста E. coli в исследуемых пробирках делали пересев петлей на плотную среду №4 (агар Эндо) и инкубировали чашки Петри в течение 24 ч при $32,5+2,5^{\circ} \mathrm{C}$. При отсутствии роста характерных малиновых колоний с металлическим блеском делали заключение об отсутствии E. coli в исследуемом образце.

Методики анализа основных БАВ побегов S. alba. Сравнение содержания БАВ в побегах $S$. alba до и после обработки гамма-облучением проводили на кафедре фармацевтической химии Пятигорского медикофармацевтического института - филиала Волгоградского государственного медицинского университета.

Для определения содержания флавоноидов получали извлечения экстракцией спиртом этиловым $70 \%$. Соотношение сырье экстрагент составляло $1: 100$. Качественное определение флавоноидов проводили с помощью цианидиновой пробы [12]. Количественное содержание флавоноидов в пересчете на рутин определяли методом дифференциальной спектрофотометрии, основанным на реакции комплексообразования с хлоридом алюминия согласно ГФ ХІ [13]. Определение проводили на спектрофотометре СФ-2000 с УФ-детектором при длине волны 410 нм. В качестве стандартного образца использовали 0,05\% раствор стандартного образца (CO) рутина в $70 \%$ этиловом спирте.

Наличие дубильных веществ (ДВ) в побегах $S$. alba доказывали химическими реакциями (с железоаммониевыми квасцами; с кислотой уксусной и свинца ацетатом) в водных извлечениях (1:10) [12]. Количественное содержание ДВ определяли перманганатометрическим методом согласно ГФ ХІ изд. (вып. 1, 1987, с.286). Кроме того, поскольку в фармакопейной статье пересчет ведется на танин, отсутствующий в объектах исследования, были внесены изменения в расчетную формулу. Пересчет вели на конденсированные ДВ, поскольку именно они преобладают в побегах S. alba [8]. При этом руководствовались ранее описанным подходом (вместо титра 0,004157 г/мл, соответствующего танину, в расчетах титр принимали равным 0,00582 г/мл) [14].

Идентификацию салицина проводили методом ТСХ в водном извлечении, полученном в соотношении 1 : 25. Хроматографирование осуществляли на пластинах Silufol в системе растворителей этилацетат муравьиная кислота - вода (80: $13: 7)$. Сравнение проводили с $0,1 \%$ раствором СО салицина в спирте этиловом 70\%. Детектирование пятен на хроматограммах осуществляли после обработки 0,5\% спиртовым раствором тимола в серной кислоте и нагревания в сушильном шкафу при температуре $120{ }^{\circ} \mathrm{C}$ в течение 3 мин [15].

\section{Обсуждение результатов}

Результаты определения содержания микроорганизмов в образцах побегов S. alba, подвергнутых различным дозировкам гамма-облучения, представлены в таблице 1.

Согласно ОФС 42-0067-07 «Микробиологическая чистота», «Лекарственные растительные средства или лекарственное сырье «ангро», применяемое без термической обработки», относится к категории 4Б. Допускается наличие в нем аэробных бактерий до $10^{5}$ в г (мл), дрожжевых и плесневых грибов до $10^{4}$ в г (мл) при отсутствии E. coli в 1 г (мл), Salmonella в 10 г или в 10 мл, энтеробактерий - не более $10^{3}$ в 1 г или в 1 мл.

Исходя из приведенных в таблице данных исследуемое сырье без использования облучения (образец №1) не соответствует требованиям ГФ по содержанию грибов. Образцы №2-6, подвергавшиеся различным дозам облучения, соответствуют рекомендуемым требованиям Государственной фармакопеи XII издания по показателю «Микробиологическая чистота», что позволяет говорить об эффективности предлагаемого метода стерилизации. Даже минимальная доза излучения $(0,25$ кГр) достаточна для деконтаминации порошка побегов $S$. alba и получения из них перорального лекарственного препарата.

Следующий этап работы - сравнение содержания основных БАВ в побегах $S$. alba до и после обработки гамма-излучением. Ранее нами предложено включить в проект фармакопейной статьи на данное 
ЛРС качественное определение салицина, флавоноидов, ДВ, количественное - суммы флавоноидов в пересчете на рутин, а также суммы дубильных (окисляемых) веществ в пересчете на конденсированные [8]. Результаты химического определения данных БАВ в изучаемом ЛРС до и после стерилизации представлены в таблице 2 .

Таким образом, ионизирующее излучение не оказывает существенного влияния на содержание основных групп БАВ в побегах S. alba.

Таблица 1. Результаты определения микробиологической чистоты побегов S. alba

\begin{tabular}{c|c|c|c|c|c}
\hline \multirow{2}{*}{ Образец } & \multicolumn{5}{|c}{ Результат } \\
\cline { 2 - 6 } & $\begin{array}{c}\text { общее число } \\
\text { аэробных бактерий }\end{array}$ & $\begin{array}{c}\text { общее число } \\
\text { грибов }\end{array}$ & Escherichia coli & Salmonella & энтеро-бактерии \\
\hline 1 & $3 \cdot 10^{4}$ & $2 \cdot 10^{4}$ & Не обнаружено & Не обнаружено & Не обнаружено \\
2 & $10^{2}$ & $3 \cdot 10^{2}$ & Не обнаружено & Не обнаружено & Не обнаружено \\
3 & $3 \cdot 10^{2}$ & $10^{2}$ & Не обнаружено & Не обнаружено & Не обнаружено \\
4 & $2 \cdot 10^{2}$ & $10^{2}$ & Не обнаружено & Не обнаружено & Не обнаружено \\
5 & $10^{2}$ & $10^{2}$ & Не обнаружено & Не обнаружено & Не обнаружено \\
6 & $10^{2}$ & Не обнаружено & Не обнаружено & Не обнаружено & Не обнаружено \\
\hline Рекомен- & Не более $10^{5}$ & Не более $10^{4}$ & Отсутстие & Отсутствие & Не более $10^{3}$ в 1 г \\
дуемые & в г или мл & в 1 г или мл & в 1 г или мл & в 10 г или 10 мл & или в 1 мл \\
нормы & & & & & \\
\hline
\end{tabular}

*Примечание: образец № 1 - сырье, не подвергавшееся облучению; образец № 2 - сырье (доза облучения 0,25 кГр), образец № 3(доза 0,5 кГр), образец № 4 (доза 1 кГр), образец № 5 (доза 2,5 кГр), образец № 6 (доза 5 кГр).

Таблица 2. Содержание БАВ в побегах $S$. alba до и после стерилизации

\begin{tabular}{|c|c|c|c|c|}
\hline Показатели & Методы & Нормы & $\begin{array}{l}\text { Результат до } \\
\text { стерилизации }\end{array}$ & $\begin{array}{c}\text { Результат после } \\
\text { стерилизации }\end{array}$ \\
\hline \multicolumn{5}{|c|}{ Подлинность } \\
\hline Салицин & TCX & $\begin{array}{c}\text { Наличие красновато-розовой } \\
\text { зоны адсорбции, соответствую- } \\
\text { щей по значению Rf CO салицина }\end{array}$ & + & + \\
\hline $\begin{array}{l}\text { Дубильные } \\
\text { вещества }\end{array}$ & $\begin{array}{l}\text { Реакция с железоаммо- } \\
\text { ниевыми квасцами }\end{array}$ & черно-зеленое окрашивание & + & + \\
\hline Флавоноиды & Цианидиновая проба & красное окрашивание & + & + \\
\hline \multicolumn{5}{|c|}{ Количественное определение } \\
\hline $\begin{array}{l}\text { Дубильные (окис- } \\
\text { ляемые) вещества }\end{array}$ & Перманганатометрия & Не менее $4,0 \%$ & $4,90 \pm 0,03 \%$ & $4,76 \pm 0,03 \%$ \\
\hline $\begin{array}{l}\text { Сумма флавонои- } \\
\text { дов в пересчете } \\
\text { на рутин }\end{array}$ & $\begin{array}{c}\text { Дифференциальная } \\
\text { СФМ по реакции ком- } \\
\text { плексо-образования с } \\
\text { алюминия хлоридом }\end{array}$ & Не менее $0,3 \%$ & $1,34 \pm 0,03 \%$ & $1,35 \pm 0,03 \%$ \\
\hline
\end{tabular}

\section{Bblвodbl}

1. Определено содержание микроорганизмов в образцах побегов $S$. alba, подвергнутых дозировкам гамма-облучения 0,25-5 кГр. После обработки излучением, начиная с минимальной дозы, порошок побегов $S$. alba соответствует рекомендуемым требованиям Государственной фармакопеи XII издания по показателю «Микробиологическая чистота», что позволяет говорить об эффективности предлагаемого метода стерилизации.

2. Ионизирующее излучение приемлемо для обработки побегов $S$. alba, поскольку существенно не влияет на качественный состав и количественное содержание основных БАВ (флавоноидов, дубильных веществ, салицина).

3. Соответствие стерилизованного сырья побегов $S$. alba нормативным требованиям по содержанию микроорганизмов открывает перспективы создания на его основе лекарственных форм для приема внутрь.

\section{Список литературы}

1. Промышленная технология лекарств: в 2-х т. / под ред. В.И. Чуешова. Харьков, 2002. Т. 2.

2. Барнаулов О.Д. Введение в фитотерапию. СПб., 1999. 160 с. 
3. Громова Е.С., Ивлева И.Н. Проблема микробиологической чистоты при производстве мягких лекарственных форм // Успехи современного естествознания. 2010. №7. С. 10-11.

4. Абдулов Р.А. Радиационная обработка пищевых продуктов, специй и вспомогательных материалов // Обеспечение единства измерений в радиационных технологиях. М., 2007. С. 182-191.

5. Чакчир О.Б. Исследование влияния ионизирующего излучения на биологически активные комплексы лекарственных растений : автореф. дис... канд. фармац. наук. М., 2013. 24 с.

6. Чакчир О.Б., Саканян Е.И., Чакчир Б.А. Исследование влияния фотонного излучения на антиаритмическую активность плодов боярышника и настоя из них // Фармация из века в век. Ч. III. Анализ и стандартизация лекарственных средств. СПб., 2008. С. 179-182.

7. White Willow Bark. URL: http://www.naturesway.com/Products/Herbs/17850-White-Willow-Bark.aspx

8. Хитева О.О. Изучение некоторых видов ивы, произрастающих на Северном Кавказе : автореф. дис. ... канд. фармац. наук. Пятигорск, 2012. 24 с.

9. Генералова В.В., Гурский М.Н. Дозиметрия в радиационной технологии. М., 2000. 184 с.

10. ОФС 42-0067-07. «Микробиологическая чистота».

11. Изменения №2 от 01.01.2002 г. к ОФС ГФ ХІ изд. «Испытание на микробиологическую чистоту».

12. Решетникова М.Д. Химический анализ биологически активных веществ лекарственного растительного сырья и продуктов животного происхождения. Пермь, 2004. С. 220-221.

13. Государственная фармакопея СССР. Вып. 2. Общие методы анализа. Лекарственное растительное сырье. 11-е изд. М., 1990. С. 323.

14. Рябинина Е.И., Зотова Е.Е., Пономарева Н.И., Рябинин С.В. Сравнительное исследование мелиссы лекарственной и шалфея лекарственного на содержание полифенолов // Вестник ВГУ. Серия: Химия. Биология. Фармация. 2009. №2. С. 49-53.

15. ТУ 9199-006-33150849-2004. Экстракт ивы сухой. Введ. 2004. СПб., 2004. 7 с.

Поступило в редакииюю 30 мая 2013 г. 
Frolova O.O..$^{*}$, Saushkina A.S. ${ }^{2}$, Mazurina M.V. ${ }^{1}$, Airapetova A.Y. ${ }^{l}$, Kompanceva Y.G. ${ }^{l}$, Kompanceva Y.V. ${ }^{l}$ STUDYING OF POSSIBILITY A WILLOW WHITE (SALIX ALBA L.) BRANCHES STERILIZATION BY IONIZING RADIATION

${ }^{1}$ Pyatigorsk Medical and Pharmaceutical Institute - a branch of Volgograd State Medical University, Kalinina ave., 11, Pyatigorsk, 357532 (Russia), e-mail: oxifarm@mail.ru

${ }_{2}^{2}$ St. Petersburg State Chemical-Pharmaceutical Academy, prof. Popova st., 14, St. Petersburg, 197376 (Russia)

There was determined a quantity of microorganisms in Salix alba L. branches specimens after processing by ionizing radiation $(0,25-5 \mathrm{kGy})$. The powder of $S$. alba branches conform to recommended requirements for a standard "Microbiological purity" after processing by the minimal radiation dose, that's why offered method of sterilization is effective. Ionizing radiation is acceptable for $S$. alba branches processing, because it doesn't influence significantly on the structure and the quantity of the main biologically active substances (flavonoids, tannins, salicine). It's possible to create medicinal forms for oral use on the native $S$. alba branches basis after carrying out sterilization by ionizing radiation.

Keywords: ionizing radiation, sterilization, microbiological purity, medicinal raw material, Salix alba L. branches.

\section{References}

1. Promyshlennaia tekhnologiia lekarstv. [Industrial technology drugs.]. Ed. V.I. Chueshov. Kharkiv, 2002, 2 vol. (in Russ.).

2. Barnaulov O.D. Vvedenie v fitoterapiiu. [Introduction to herbal medicine.]. 1999. 160 p. (in Russ.).

3. Gromova E.S., Ivleva I.N. Uspekhi sovremennogo estestvoznaniia, 2010, no. 7, pp. 10-11. (in Russ.).

4. Abdulov R.A. Obespechenie edinstva izmerenii v radiatsionnykh tekhnologiiakh. [Ensuring the uniformity of measurements in radiation technologies.]. Moscow, 2007, pp. 182-191. (in Russ.).

5. Chakchir O.B. Issledovanie vliianiia ioniziruiushchego izlucheniia na biologicheski aktivnye kompleksy lekarstvennykh rastenii: avtoref. dis... kand. farmats. nauk. [Investigation of the influence of ionizing radiation on biologically active complexes of medicinal plants: summary of dissertation of Pharmaceutical Sciences]. Moscow, 2013, 24 p. (in Russ.).

6. Chakchir O.B., Sakanian E.I., Chakchir B.A. Farmatsiia iz veka v vek. Chast' III. Analiz i standartizatsiia lekarstvennykh sredstv. [Pharmacy from century to century. Part III. Analysis and standardization of medicines.]. St. Petersburg, 2008, pp. 179-182. (in Russ.).

7. White Willow Bark. URL: http://www.naturesway.com/Products/Herbs/17850-White-Willow-Bark.aspx

8. Khiteva O.O. Izuchenie nekotorykh vidov ivy, proizrastaiushchikh na Severnom Kavkaze: avtoref. dis... kand. farmats. nauk. [The study of certain species of willow growing in the North Caucasus: summary of dissertation of Pharmaceutical Sciences]. Pyatigorsk, 2012, 24 p. (in Russ.).

9. Generalova V.V., Gurskii M.N. Dozimetriia v radiatsionnoi tekhnologii. [Dosimetry in radiation technology]. Moscow, 2000, 184 p. (in Russ.).

10. OFS 42-0067-07. Mikrobiologicheskaia chistota. [Overall Pharmacopeial article 42-0067-07. Microbiological purity]. (in Russ.).

11. Izmeneniia №2 ot 01.01.2002 g. $k$ OFS GF XI izd. «Ispytanie na mikrobiologicheskuiu chistotu». [Change number 2 from 01.01.2002 to the General State Pharmacopoeia Pharmacopoeia article. XI ed. "The test for microbiological purity"]. (in Russ.).

12. Reshetnikova M.D. Khimicheskii analiz biologicheski aktivnykh veshchestv lekarstvennogo rastitel'nogo syr'ia $i$ produktov zhivotnogo proiskhozhdeniia. [Chemical analysis of biologically active substances of medicinal plants and animal products]. Perm, 2004, pp. 220-221. (in Russ.).

13. Gosudarstvennaia farmakopeia SSSR. Vyp. 2. Obshchie metody analiza. Lekarstvennoe rastitel'noe syr'e. 11-e izd. [USSR State Pharmacopoeia. Issue 2. Common methods of analysis. Herbal drugs. 11th ed.]. Moscow, 1990, p. 323. (in Russ.).

14. Riabinina E.I., Zotova E.E., Ponomareva N.I., Riabinin S.V. Vestnik VGU. Seriia: Khimiia. Biologiia. Farmatsiia, 2009, no. 2, pp. 49-53. (in Russ.).

15. TU 9199-006-33150849-2004. Ekstrakt ivy sukhoi. [Specifications 9199-006-33150849-2004. Willow extract dry]. St. Petersburg, 2004, 7 p. (in Russ.).

\footnotetext{
* Corresponding author.
} 